\title{
Neuropsychological Characteristics and Their Association with Higher-Level Functional Capacity in Parkinson's Disease
}

\author{
Kayoko Miura $^{a, b}$ Mie Matsui $^{a}$ Shutaro Takashima ${ }^{c}$ Kortaro Tanakac \\ a Department of Psychology, Graduate School of Medicine and Pharmaceutical Sciences, \\ University of Toyama, ${ }^{b}$ Japan Society for the Promotion of Science, and ${ }^{\mathrm{C}}$ Department of \\ Neurology, Toyama University Hospital, Toyama, Japan
}

\section{Key Words}

Parkinson's disease $\cdot$ Neuropsychological characteristics $\cdot$ Cognitive function $\cdot$ Higher-level functional capacity $\cdot$ Intellectual activity $\cdot$ Social identity $\cdot$ Social participation

\begin{abstract}
Background/Aims: Little is known about the relationship between cognitive functions and higher-level functional capacity (e.g. intellectual activity, social role, and social participation) in Parkinson's disease (PD). The purpose of this study was to clarify neuropsychological characteristics and their association with higher-level functional capacity in PD patients. Methods: Participants were 31 PD patients and 23 demographically matched healthy controls. Neuropsychological tests were conducted. One year later, a questionnaire survey evaluated higherlevel functional capacity in daily living. Results: The PD group scored significantly lower than the control group in all cognitive domains, particularly executive function and processing. Executive function, processing speed, language, and memory were significantly correlated with higher-level functional capacity in PD patients. Stepwise regression showed that only executive function (Trail Making Test-B), together with disease severity (HY stage), predicted the higher-level functional capacity. Conclusion: Our findings provide evidence of a relationship between executive function and higher-level functional capacity in patients with PD.
\end{abstract}

(C) 2015 S. Karger AG, Base

\section{Introduction}

An important part of successful aging is the strengthening of various functions such as motor function, sensory function, and physiological function. Medical researchers and healthcare professionals should support elderly people to maintain both their physical and 
mental health so that they can remain highly motivated and make full use of their abilities. However, individual differences in physical function, mental health, and cognitive function increase with age. Moreover, in patients with chronic illnesses, disease-specific factors affect various functions. Therefore, the factors related to successful aging need to be considered on a disease-specific basis.

Parkinson's disease (PD) is a chronic and progressive neurodegenerative disorder that is mainly caused by dopaminergic neuron loss in the substantia nigra. PD typically develops after late middle age, and incidence rates increase with age. The most common symptoms include resting tremor, rigidity, bradykinesia, and postural instability. In recent years, recognition of the importance of nonmotor PD symptoms (e.g. cognitive impairment, emotional problems, and sleep problems) has increased. Cognitive impairment is a particular problem as it reduces quality of life [1-3].

In one multicenter cohort study, $25.8 \%$ of patients with PD were classified as having mild cognitive impairment (MCI) [4]. Another survey reported that $18.9 \%$ of patients with drugnaïve PD were classified as having MCI [5]. Cognitive function problems in PD are diverse, including executive functions, attention, memory, language, and visuospatial function. These impairments represent frontostriatal neuronal circuitry dysfunction; the impairment of frontal executive function constitutes the core feature of neuropsychological dysfunction in PD. In many cases, patients are often not aware of their own cognitive dysfunction, but comprehensive neuropsychological tests can detect even subtle impairments. Since the primary symptoms in PD relate to motor function, it is possible that cognitive impairments are less salient, making it difficult to discern their impact on daily life.

One study of community-dwelling elderly people indicated that problems with cognitive as well as physical function significantly impact the maintenance of daily function, even when demographic variables and illness variables are controlled for [6]. Relatively few studies have examined the association of daily function and cognitive function in PD patients without dementia [7-10]. Cahn et al. [7] reported that motor functioning was a significant independent predictor of physical activities of daily living (ADL; e.g. eating, grooming), whereas executive functioning was not. In contrast, executive functioning (particularly sequencing), but not motor functioning, was a significant independent predictor of instrumental ADL (IADL; e.g. shopping, dialing a telephone number). Rosenthal et al. [8] found relationships between cognitive impairment and ADL, including difficulties in IADL, in patients with PD. Martin et al. [9] reported impairment of financial capacity in PD with MCI (PD-MCI), indicating that cognitive function is associated with IADL. Another study demonstrated that performance-based measures of IADL, particularly medication management ability, are sensitive to subtle functional declines in PD-MCI [10]. However, these authors suggest that IADL and cognitive functioning may be separate domains of functioning in PD-MCI, as IADL measures did not correlate with performance on neuropsychological measures.

There are various levels of daily function. Lawton [11] developed a hierarchical model of competence comprising seven sublevels: life maintenance, functional health, perception and cognition, physical self-maintenance, instrumental self-maintenance, effectance, and social role. Based on Lawton's model, Koyano et al. [12] developed the Tokyo Metropolitan Institute of Gerontology Index of Competence (TMIG-IC). The TMIG-IC was designed to measure three higher-level functional capacities. Higher-level competence, which indicates a higher-level functional capacity above basic ADL, corresponds to the 5th, 6th, and 7th sublevels of Lawton's hierarchical model. Expanding on the concept of the three TMIG-IC categories, Masui et al. [13] developed the Japan Science and Technology Agency Index of Competence (JST-IC). This measures a higher level of daily function that includes newly added components, such as social participation and life management. To promote successful aging in an elderly society, 
Table 1. Demographic and clinical characteristics of the study participants

\begin{tabular}{|c|c|c|c|}
\hline \multicolumn{4}{|c|}{ Dement Geriatr Cogn Disord Extra 2015;5:271-284 } \\
\hline DOI: $10.1159 / 000381333$ & \multicolumn{3}{|c|}{$\begin{array}{l}\text { (C) } 2015 \text { S. Karger AG, Basel } \\
\text { www.karger.com/dee }\end{array}$} \\
\hline \multicolumn{4}{|c|}{$\begin{array}{l}\text { Miura et al.: Neuropsychological Characteristics and Their Association with } \\
\text { Higher-Level Functional Capacity in Parkinson's Disease }\end{array}$} \\
\hline & & $\mathrm{PD}(\mathrm{n}=32)$ & $\mathrm{HC}(\mathrm{n}=25)$ \\
\hline \multicolumn{2}{|l|}{ Age, years } & $67.8 \pm 7.4$ & $66.9 \pm 7.2$ \\
\hline \multicolumn{2}{|l|}{ Men/women } & $10 / 22$ & $9 / 16$ \\
\hline \multicolumn{2}{|l|}{ Education, years } & $12.0 \pm 1.6$ & $13.2 \pm 2.6$ \\
\hline \multicolumn{2}{|l|}{ Premorbid IQ } & $97.0 \pm 12.4$ & $104.6 \pm 10.4$ \\
\hline \multicolumn{2}{|l|}{ MMSE-J } & $28.5 \pm 1.6$ & $29.3 \pm 1.1$ \\
\hline \multicolumn{2}{|l|}{ Disease duration, years } & $5.6 \pm 4.6$ & - \\
\hline \multicolumn{2}{|l|}{ LEDD, mg } & $318.9 \pm 187.6$ & - \\
\hline \multicolumn{2}{|c|}{ HY distribution, 1/2/3/4/5 } & $0 / 9 / 23 / 0 / 0$ & - \\
\hline
\end{tabular}

All values represent mean \pm SD. Premorbid IQ was estimated using the Japanese Adult Reading Test.

it is important to maintain not just ADL and IADL, but also a higher level of daily function. Higher-level functional capacity reflects a more active and healthy aging, and independent living, compared with ADL and IADL. However, many studies on PD have focused on ADL and IADL rather than higher-level functional capacity.

While there is no clear definition of 'successful aging', Rowe and Kahn [14] have enumerated three important characteristics: (1) low probability of disease, (2) high cognitive and physical function, and (3) active engagement with life. As PD is a chronic, progressive neurological disorder that mainly affects motor function, physical function gradually deteriorates. Thus, the key to successful aging might be the maintenance of cognitive function and everyday function.

Accordingly, we will focus on the following questions: (a) What are the features of neuropsychological function and higher-level functional capacity in patients with PD? (b) Do neuropsychological characteristics affect higher-level functional capacity after 1 year in patients with PD? (c) What cognitive domains affect higher-level functional capacity in PD patients? Investigating the relationship between neuropsychological characteristics and higher-level functional capacity in PD in older people might help improve quality of life, and facilitate successful aging in patients with PD. We hypothesized that: (1) PD patients would score significantly lower on all cognitive domains, particularly executive function and attention, than healthy controls (HC), and (2) cognitive function would impact the subsequent daily life functions of PD patients.

\section{Materials and Methods}

\section{Participants}

Summary statistics of the participants' demographic and clinical characteristics are reported in table 1 . For the comparison of neuropsychological function, we had available the data of 57 participants (PD group: 32, HC group: 25; fig. 1). For the questionnaire component of the study, 3 participants were excluded, leaving 31 patients with PD (PD group: 9 men, 22 women) and 23 demographically matched HC (HC group: 9 men, 14 women). The patients were recruited from the outpatient department at Toyama University Hospital. The HC participants were recruited from the community. Participants were excluded from the study if they had (a) a Mini-Mental State Examination-Japanese (MMSE-J) total score <25, (b) a history of any other neurological disorder and/or acquired brain injury, and (c) a history of serious mental illness. 
Fig. 1. Flowchart showing study design.

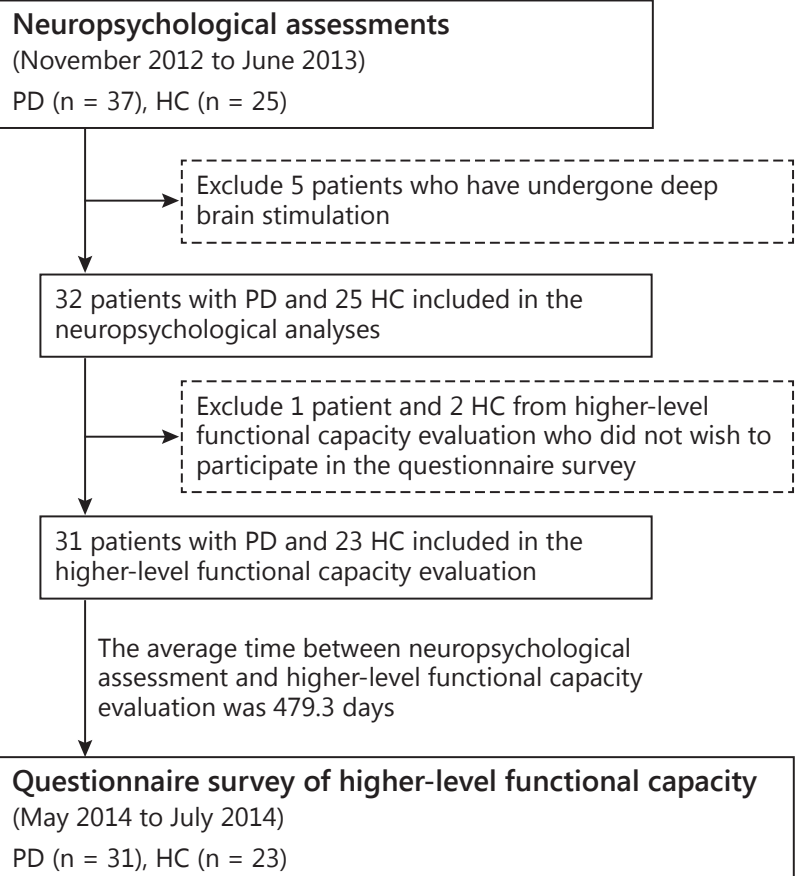

Study Design

This study was designed to clarify the neuropsychological characteristics of PD and their association with higher-level functional capacity. The following tests were conducted to identify neuropsychological characteristics in patients with PD: the Wisconsin Card Sorting Test (WCST) [15], the Trail Making Test (TMT) $[16,17]$ the Digit Span Test (DST) [18], the Verbal Fluency Test (VFT) [17, 19], and the Japanese Verbal Learning Test (JVLT) [20].

About 1 year after testing, we performed a questionnaire survey to evaluate higher-level functional capacity in daily living. The average period between the neuropsychological testing and the higher-level functional capacity evaluation was 479.3 days.

All patients with PD were medicated with antiparkinsonian drugs at the time of neuropsychological testing and questionnaire evaluation. Doses of dopaminergic medication were converted to an L-dopa-equivalent daily dose (LEDD) [21]. All evaluations were approved by the Ethics Committee of the University of Toyama, and all participants signed a written consent form before undergoing the assessment. A flowchart of the study is presented in figure 1.

\section{Assessments}

\section{Clinical Characteristics}

The severity of disease was rated by at least one neurologist using the Hoehn and Yahr (HY) rating scale. Before performing the neuropsychological tests, the level of global cognitive function was confirmed using the MMSE-J. Premorbid intelligence was estimated using the Japanese Adult Reading Test [22]. The level of apathy was assessed using the Japanese version of the Apathy Scale [23]. Other patient characteristics were collected from electronic medical records. 
Neuropsychological Characteristics

Details of the neuropsychological assessment are as follows. Executive function was assessed using the WCST and TMT-B. The WCST consists of 4 stimulus cards and 2 identical decks of 64 response cards. The response cards display different numbers of figures of varying forms and colors. Participants must match a set of response cards to one of the stimulus cards. They are not told how to match the cards (by the rule of color, form, or number), but are told which matches are correct or incorrect. The WCST measures executive functions, mental flexibility, problem-solving ability, and set-shifting ability [19]. The TMT consists of two parts (A and B). In part B (TMT-B), the participant must connect circles with alternating numbers and letters. TMT-B measures executive function, cognitive flexibility, and alternating attention because it requires the capacity to switch from one stimulus to another. The TMT (B - A) is able to accurately evaluate PD patients' ability to switch attention because it eliminates the influence of motor speed [24]. Attention and working memory were assessed using the DST from the 3rd edition of the Wechsler Adult Intelligence Scale. The DST measures auditory attention by requiring repetition of a series of digits immediately following presentation. Processing speed was assessed using the TMT-A, which requires participants to connect numbered circles scattered across a page. TMT-A measures visual scanning, numeric sequencing, and visuomotor speed. The VFT (category and letter) was used to assess language. Individuals must generate as many words as possible, according to particular rules, during a specified time interval. Participants were asked to generate words within both a semantic category (animal), and a phonemic category (beginning with 'ka'). Verbal memory and learning was assessed using the JVLT. This is the original Japanese verbal learning test referring to specific characteristics of the unblocked list of another previous study [25], similar to the California Verbal Learning Test [26]. The examiner reads aloud a list of 16 words at 1-second intervals in a fixed order over three trials. After each trial, participants must recall as many words as they can in any order. Delay free recall was tested after a 15- to 20-min interval (in which the subject was occupied with other tests).

\section{Higher-Level Functional Capacity}

Higher-level functional capacity was assessed using the TMIG-IC and the JST-IC. The TMIG-IC has been widely used in Japan, and has good validity and reliability [27]. It comprises a 13-item index including three sublevels of competence: instrumental self-maintenance (e.g. Can you handle your own banking?), intellectual activity (e.g. Do you read books or magazines?), and social role (e.g. Do you visit the homes of friends?). Although the TMIG-IC has become a standard measure of competence in the elderly, its format is now a little dated. In addition, some questions may not be as relevant to elderly people today. For this reason, the JST-IC was created to reflect changes in social conditions and trends. The JST-IC is a 16-item index with four sublevels of competence: social participation (e.g. Are you active in the neighborhood association and residents' association?), use of new devices (e.g. Can you use the automated teller machine?), information gathering (e.g., Do you watch educational programs?), and life management (e.g. Do you make some small creative arrangements in your daily life?). Used in conjunction with the TMIG-IC, the JST-IC can be applied to a broader group of people. Both the TMIG-IC and JST-IC were administered to both groups of participants who were asked to evaluate feasibility or their own independence with respect to the 29 tasks. The response to each item was 'yes' (able to do) or 'no' (unable to do), and scored as 1 for 'yes' and 0 for 'no'.

\section{Statistical Analysis}

Group differences on neuropsychological measures and higher-level functional capacity measures were analyzed using independent $t$ tests and Mann-Whitney $U$ tests, respectively. 
Miura et al.: Neuropsychological Characteristics and Their Association with

Higher-Level Functional Capacity in Parkinson's Disease

Correlation between Neuropsychological Characteristics and Higher-Level Functional Capacity

First, Spearman's correlational analysis was used to examine relationships between neuropsychological characteristics and higher-level functional capacity in the PD group. Second, neuropsychological variables that significantly correlated with higher-level functional capacity were entered into a stepwise multiple regression analysis to determine their relative contribution to higher-level functional capacity. Third, the raw neuropsychological test scores of the PD group were converted to z-scores using the mean and SD of the same generation $\mathrm{HC}$ group. PD participants with an observed z-score falling more than $-1.5 \mathrm{SD}$ below the mean were classified as demonstrating cognitive decline. The Kruskal-Wallis test was used to compare subscale scores on the TMIG-IC and JST-IC between the three groups (HC vs. PD with cognitive impairment vs. PD with normal cognitive function). Post hoc analysis used the Mann-Whitney test with Bonferroni adjustment.

\section{Results}

Group Differences in Neuropsychological Characteristics

Group comparisons of neuropsychological characteristics are shown in table 2. Patients with PD performed significantly worse than the HC group in all domains. In the executive function test, the PD group achieved significantly fewer categories, made more total errors, showed higher rates of nonperseverative errors, and fewer conceptual level responses on the WCST than did the HC group. In addition, the PD group performed significantly worse than the HC group on TMT-B and TMT (B - A). The PD group had significantly lower scores on attention/working memory in the backward version of the DST. Regarding processing speed, the PD group performed significantly worse than the HC group on TMT-A. In relation to language, the PD group was more impaired on letter fluency tasks than the HC group. Regarding memory and learning, the PD group performed significantly worse on immediate recall than the HC group. There were large effect sizes for completed WCST categories TMT-B and TMT-A.

\section{Group Differences in Higher-Level Functional Capacity}

Group comparisons of higher-level functional capacity are shown in table 3 . The mean TMIG-IC score for the PD group was $10.6 \pm 2.9$, and for the HC group it was $12.4 \pm 1.2$. The PD group showed significantly lower total TMIG-IC scores than the HC group. PD patients had significantly lower scores than the HC group on the Instrumental self-maintenance and the Intellectual activity subscales, but not on the Social role subscale. The mean JST-IC score for the PD group was $10.8 \pm 3.6$, and for the HC group it was $13.6 \pm 2.9$. PD patients had significantly lower scores than the HC group on the Social participation, Use of new devices and Information gathering subscales, but not on the Life management subscale.

\section{Correlation between Neuropsychological Characteristics and Higher-Level Functional} Capacity

The results of this analysis are presented in tables 4 and 5. Higher-level functional capacity (integration score $=$ sum of TMIG-IC and JST-IC) was significantly correlated with the following neuropsychological characteristics: executive function (WCST total errors and TMT-B), processing speed (TMT-A), language (VFT category), and memory (JVLT). We conducted a stepwise multiple regression analysis to evaluate the influence of these neuropsychological characteristics on higher-level functional capacity. Age, HY stage, and LEDD were also included in this analysis. Regression results revealed significant changes in $\mathrm{R}^{2}$ at 
Table 2. Neuropsychological characteristics of patients with PD and HC, matched for age and education

\begin{tabular}{|c|c|c|c|c|c|}
\hline Domain and measure & $\begin{array}{l}\text { PD } \\
(n=32)\end{array}$ & $\begin{array}{l}\mathrm{HC} \\
(n=25)\end{array}$ & $\mathrm{t}$ & $\mathrm{p}$ value & $\begin{array}{l}\text { Effect size, } \\
\text { Cohen's d }\end{array}$ \\
\hline \multicolumn{6}{|l|}{ Executive function } \\
\hline \multicolumn{6}{|l|}{ WCST } \\
\hline Categories completed & $4.7 \pm 2.2$ & $6.0 \pm 0.0$ & 3.10 & $0.004^{* *}$ & 0.81 \\
\hline Total errors & $27.8 \pm 22.0$ & $14.9 \pm 6.5$ & -3.01 & $0.005^{* *}$ & 0.77 \\
\hline Perseverative errors, \% & $10.5 \pm 4.5$ & $8.8 \pm 2.3$ & -1.90 & 0.064 & 0.47 \\
\hline Nonperseverative errors, $\%$ & $15.0 \pm 11.5$ & $8.5 \pm 3.1$ & -2.91 & $0.006^{* *}$ & 0.75 \\
\hline Conceptual level responses, $\%$ & $65.6 \pm 22.0$ & $76.7 \pm 6.7$ & 2.57 & $0.015^{*}$ & 0.66 \\
\hline TMT-B, s & $154.8 \pm 102.8$ & $91.2 \pm 29.5$ & -3.33 & $0.002^{* *}$ & 0.80 \\
\hline TMT $(B-A), s$ & $82.2 \pm 64.0$ & $52.3 \pm 25.3$ & -2.41 & $0.020^{*}$ & 0.59 \\
\hline \multicolumn{6}{|l|}{$\begin{array}{l}\text { Attention/working memory } \\
\text { DST }\end{array}$} \\
\hline Forward & $5.2 \pm 1.8$ & $5.5 \pm 1.0$ & 1.00 & 0.321 & 0.20 \\
\hline Backward & $3.9 \pm 0.8$ & $4.4 \pm 1.1$ & 2.06 & $0.045^{*}$ & 0.53 \\
\hline \multicolumn{6}{|l|}{ Processing speed } \\
\hline TMT-A, s & $72.6 \pm 50.5$ & $38.9 \pm 10.0$ & -3.68 & $0.001^{* *}$ & 0.88 \\
\hline \multicolumn{6}{|l|}{ Language } \\
\hline \multicolumn{6}{|l|}{ VFT } \\
\hline Letter (Ka) & $9.3 \pm 3.2$ & $11.6 \pm 2.8$ & 2.92 & $0.005^{* *}$ & 0.76 \\
\hline Category (animal) & $16.3 \pm 6.5$ & $18.0 \pm 5.5$ & 1.05 & 0.298 & 0.28 \\
\hline \multicolumn{6}{|l|}{ Memory and learning } \\
\hline \multicolumn{6}{|l|}{ JVLT } \\
\hline Immediate recall total & $30.1 \pm 7.6$ & $35.0 \pm 4.9$ & 2.76 & $0.005^{* *}$ & 0.75 \\
\hline Immediate recall trial 1 & $6.7 \pm 2.9$ & $7.8 \pm 2.2$ & 1.63 & 0.108 & 0.42 \\
\hline Immediate recall trial 2 & $11.3 \pm 2.8$ & $13.1 \pm 1.8$ & 2.87 & $0.006^{* *}$ & 0.75 \\
\hline Immediate recall trial 3 & $12.2 \pm 2.9$ & $14.0 \pm 1.9$ & 2.81 & $0.005^{* *}$ & 0.72 \\
\hline Delayed recall & $12.1 \pm 2.8$ & $13.3 \pm 2.0$ & 1.89 & 0.065 & 0.48 \\
\hline
\end{tabular}

Groups were compared by independent $t$ test. Values represent mean \pm SD. ${ }^{*} \mathrm{p}<0.05 ;{ }^{* *} \mathrm{p}<0.01$.

Cohen's d: $\geq 0.8=$ large, $0.5-0.8=$ medium, $0.2-0.5=$ small.

Table 3. Scores of the Tokyo Metropolitan Institute of Gerontology Index of Competence and the Japan Science and Technology Agency Index of Competence: comparison between PD and HC

\begin{tabular}{lrrl}
\hline & PD $(\mathrm{n}=31)$ & $\mathrm{HC}(\mathrm{n}=23)$ & $\mathrm{p}$ value \\
\hline TMIG-IC & $10.58 \pm 2.93$ & $12.43 \pm 1.20$ & $0.002^{* *}$ \\
Instrumental self-maintenance & $4.06 \pm 1.39$ & $4.96 \pm 0.21$ & $0.002^{* *}$ \\
Intellectual activity & $3.39 \pm 0.84$ & $4.00 \pm 0.00$ & $0.000^{* * *}$ \\
Social role & $3.13 \pm 1.26$ & $3.48 \pm 1.20$ & 0.054 \\
\hline JST-IC & $10.84 \pm 3.56$ & $13.65 \pm 2.89$ & $0.003^{* *}$ \\
Social participation & $1.65 \pm 1.50$ & $3.09 \pm 1.35$ & $0.000^{* * *}$ \\
Use of new devices & $2.90 \pm 1.25$ & $3.61 \pm 0.66$ & $0.032^{*}$ \\
Information gathering & $3.23 \pm 0.85$ & $3.57 \pm 0.95$ & $0.041^{*}$ \\
Life management & $3.06 \pm 1.06$ & $3.39 \pm 0.89$ & 0.257 \\
\hline
\end{tabular}

Groups were compared using Mann-Whitney U tests. Values represent mean \pm SD. * $\mathrm{p}<0.05$; ** $\mathrm{p}<0.01$; *** $\mathrm{p}<0.001$. 


\begin{tabular}{l|l}
\hline DOI: 10.1159/000381333 & $\begin{array}{l}\text { C } 2015 \text { S. Karger AG, Basel } \\
\text { www.karger.com/dee }\end{array}$ \\
\hline Miura et al.: Neuropsychological Characteristics and Their Association with \\
Higher-Level Functional Capacity in Parkinson's Disease
\end{tabular}

Table 4. Correlations between neuropsychological characteristics and higher-level functional capacity in patients with PD (n=31)

\begin{tabular}{ll}
\hline Domain and measure & Integration score \\
\hline Executive function & \\
WCST & $0.454^{*}$ \\
$\quad$ Categories completed & $-0.398^{*}$ \\
$\quad$ Total errors & -0.130 \\
$\quad$ Perseverative errors (\%) & $-0.415^{*}$ \\
$\quad$ Nonperseverative errors (\%) & 0.324 \\
$\quad$ Conceptual level responses (\%) & $-0.605^{* *}$ \\
TMT-B (s) & $-0.521^{* *}$ \\
TMT (B - A) (s) & \\
\hline Attention/working memory & 0.360 \\
DST & 0.209 \\
$\quad$ Forward & $-0.649^{* *}$ \\
$\quad$ Backward & \\
\hline Processing speed & \\
TMT-A (s) & 0.250 \\
\hline Language & $0.528^{* *}$ \\
VFT & \\
$\quad$ Letter (Ka) & $0.405^{*}$ \\
Category (animal) & \\
\hline Memory and learning & \\
JVLT - Immediate recall total & \\
\hline Integration score is the sum of TMIG-IC and JS. ${ }^{*} \mathrm{p}<0.05 ; * * \mathrm{p}<$ \\
0.01.
\end{tabular}

Table 5. Results of stepwise multiple regression analysis of factors influencing higher-level functional capacity of patients with PD $(\mathrm{n}=31)$

\begin{tabular}{lllllll}
\hline & $\mathrm{R}^{2}$ & Change in $\mathrm{R}^{2}$ & Adjusted $\mathrm{R}^{2}$ & $\beta$ & $\mathrm{t}$ & $\mathrm{p}$ value \\
\hline $\begin{array}{l}\text { Step1 } \\
\text { HY stage }\end{array}$ & 0.41 & & 0.39 & & & \\
\hline $\begin{array}{l}\text { Step 2 } \\
\quad \text { HY stage }\end{array}$ & & & & -0.637 & -4.455 & $0.000^{* * *}$ \\
$\quad$ TMT-B & 0.52 & 0.11 & 0.49 & & & \\
& & & & -0.369 & -2.562 & $0.016^{*}$ \\
& & & & -0.484 & -3.357 & $0.002^{* *}$ \\
\hline
\end{tabular}

Dependent variable: integration score. Final model: $\mathrm{R}=0.720, \mathrm{~F}(2,28)=15.11, \mathrm{p}<0.001{ }^{*} \mathrm{p}<0.05$; $* * \mathrm{p}<0.01 ; * * * \mathrm{p}<0.001$.

the first and second steps. At step 1, HY stage accounted for $41 \%$ of the variance. When TMT-B was added at step 2 , a further $11 \%$ of the variance was accounted for $\left(\mathrm{R}^{2}\right.$ total $\left.=0.52\right)$.

Comparison between the HC, PD with Cognitive Decline, and PD without Cognitive Decline Groups on Each TMIG-IC and JST-IC Subscale

Patients with PD were classified into 'PD-executive impairment' and 'PD-normal executive function' based on the TMT-B z-score, because TMT-B is related to higher-level functional capacity. Group comparisons of TMIG-IC and JST-IC subscales are shown in table 6. 
Table 6. Comparison of TMIG-IC and JST-IC subscales across groups

\begin{tabular}{|c|c|c|c|c|c|c|}
\hline & $\begin{array}{l}\mathrm{HC} \\
(\mathrm{n}=23)\end{array}$ & $\begin{array}{l}\text { PD-normal } \\
\text { executive } \\
(\mathrm{n}=19)\end{array}$ & $\begin{array}{l}\text { PD-executive } \\
\text { impairment } \\
(\mathrm{n}=12)\end{array}$ & $\begin{array}{l}\text { Kruskal- } \\
\text { Wallis } \chi^{2}\end{array}$ & $\mathrm{p}$ value & Post hoc analysis \\
\hline \multicolumn{7}{|l|}{$T M I G-I C$} \\
\hline Instrumental self-maintenance & 33.5 & 29.0 & 13.6 & 21.8 & $0.000^{* * *}$ & $\begin{array}{l}\text { HC, PD-normal executive > } \\
\text { PD-executive impairment }\end{array}$ \\
\hline Intellectual activity & 34.0 & 28.8 & 12.9 & 25.7 & 0.000 & $\begin{array}{l}\text { HC, PD-normal executive > } \\
\text { PD-executive impairment }\end{array}$ \\
\hline Social role & 31.6 & 27.9 & 19.5 & 6.4 & $0.040^{*}$ & HC > PD-executive impairment \\
\hline \multicolumn{7}{|l|}{$J S T-I C$} \\
\hline Social participation & 35.8 & 24.9 & 15.7 & 14.5 & $0.001^{* * *}$ & $\begin{array}{l}\text { HC > PD-executive impairment, } \\
\text { PD-normal executive }\end{array}$ \\
\hline Use of new devices & 32.3 & 29.7 & 14.8 & 12.8 & $0.002^{* *}$ & $\begin{array}{l}\text { HC, PD-normal executive > } \\
\text { PD-executive impairment }\end{array}$ \\
\hline Information gathering & 32.0 & 27.5 & 18.9 & 7.0 & $0.030^{*}$ & $\begin{array}{l}\text { HC > PD-executive impairment, } \\
\text { PD-normal executive }\end{array}$ \\
\hline Life management & 30.1 & 31.5 & 16.2 & 9.6 & $0.008^{* *}$ & $\begin{array}{l}\text { HC, PD-normal executive > } \\
\text { PD-executive impairment }\end{array}$ \\
\hline
\end{tabular}

Groups were compared using the Kruskal-Wallis test. Bonferroni-adjusted Mann-Whitney U tests were used as post hoc analysis. Values represent mean rank. ${ }^{*} \mathrm{p}<0.05$; $^{* *} \mathrm{p}<0.01$; ${ }^{* * *} \mathrm{p}<0.001$.

There were significant differences between the three groups for all subscales. The PD-executive impairment group scored significantly lower than the HC and PD-normal executive function groups on the Instrumental self-maintenance, Intellectual activity, Use of new devices, and Life management subscales. The PD-executive impairment group scored significantly lower than the HC group on the Social role subscale. Both PD groups scored significantly lower than the HC group on the Social participation and Information gathering subscales.

\section{Discussion}

The primary aim of the present work was to clarify the neuropsychological characteristics of PD and their association with higher-level functional capacity. The PD group scored significantly lower on all cognitive domains compared with the HC group, with large effect sizes for the WCST, TMT-A, and TMT-B tests. These results support our hypothesis that PD patients perform poorly in all cognitive domains, but especially executive function and attention. However, TMT performance is affected by motor function. Since patients with PD experience motor symptoms, their actions were slower compared to the HC group. TMT (B - A) scores showed a small effect size compared to TMT-B and TMT-A, although we used the difference score $(B-A)$, which is meant to remove the motor component of the test evaluation. The magnitude of the effect sizes in TMT-A and TMT-B suggests that motor function is involved, but it is not clear whether this solely reflects the decrease in executive function. However, the PD group showed significantly lower scores on the DST (backward) and letter fluency test than the HC group. Working memory and divided attention are involved in the backward DST because this test involves a reversing operation (mental double-tracking) as well as a memory component [19]. In addition, compared with the category fluency, the letter 
Miura et al.: Neuropsychological Characteristics and Their Association with

Higher-Level Functional Capacity in Parkinson's Disease

fluency task reflects frontal lobe function to a larger extent. For this reason, it is suggested that frontal lobe function declines in PD groups, and this is supported by a recent metaanalysis $[28,29]$ indicating that attention and executive function are impaired in PD patients.

There has been a recent increase in reports of brain changes associated with cognitive impairment [30-32]. In an MRI study, patients with PD-MCI had significantly decreased gray matter density in the right middle frontal area compared with patients with PD-intact cognition [30]. Several studies using diffusion tensor imaging have shown that changes in the microstructure of white matter in PD patients are associated with cognitive function. For example, Gallagher et al. [31] showed that fractional anisotropy within an a priori frontal mask was related to executive composite scores. They concluded that white matter microstructural abnormalities contribute to cognitive deficits in PD. Zheng et al. [32] investigated the relationship between measures of white matter integrity in regions of interest and performance in five distinct cognitive domains (executive function, language, attention, memory, and visuospatial skills). They demonstrated that executive function is primarily correlated with frontal connecting tracts, including the left anterior limb of the internal capsule and genu of the corpus callosum. These results indicate that the executive function impairments in PD are related to anatomical changes in the frontal lobe area. Thus, the prior research suggests that cognitive functions in PD (e.g. executive functions) are impaired by microstructural changes of the frontal area. Future work requires prospective observation of cognitive and brain changes. Investigating longitudinal changes of cognitive impairment in PD patients may be helpful in understanding their cognitive symptoms.

It is important to recognize changes in the functional capacity of patients with PD in order to fully understand their substantial difficulties in daily life. Patients with PD showed a decrease in higher-level functional capacity in comparison with HC. The final regression model significantly predicted higher-level functional capacity, with symptom severity (HY stage) and executive function (TMT-B) as the strongest predictors. It is interesting that TMT-B was selected as a predictive factor because it is related to executive function. In addition to the severity of symptoms, TMT-B showed promise as a predictive factor for higher-functional capacity. Using the TMT-B results, we divided PD patients into those showing executive function impairment and those not showing executive function impairment.

The group showing executive impairment scored lower on instrumental self-maintenance, intellectual activities, the use of new devices, and life management compared to those not showing the impairment, and the HC group. However, there was no significant difference in scores between the latter two groups. Our results support the findings of previous studies of MCI [33] and PD [7], which report that executive function is significantly related to instrumental self-maintenance. Because executive function controls the ability to actualize decisionmaking, planning, executing, and modifying as a sequential cognitive function, IADL - which requires complex and applied behavior in comparison to ADL - is strongly influenced by executive function. A study of Japanese regional senior residents found that higher-level functional capacity correlated positively with cognitive function [34]. In particular, intellectual activities seem largely determined by the cognitive function that controls information processing speed, executive function, and short-term memory or working memory. Example TMIG-IC questions that examine intellectual activities, and involve cognitive functioning aspects, are: 'Do you read newspapers?' and 'Are you able to fill out forms for your pension?' Our findings indicate a correlation between intellectual activity and executive function.

The ability to use new devices is also correlated with executive function. The use of a new device does not simply involve temporarily gathering information. If the new device has a display, for example, the user must remember information while simultaneously reading the screen, necessitating multiple cognitive processes [35]. These simultaneous and parallel functions of storing and modifying are related to working memory capacity. In this study, PD 
patients who were impaired in their performance on the TMT-B were classified as 'PD-executive function impairment,' but TMT-B scores reflect alternative and divided attention, as well as working memory. As elderly individuals age, the decline in executive function and attention becomes more pronounced, and they tend to avoid using devices that require complex cognitive functioning. This indicates that if executive function is reduced, the use of information and communication equipment can be difficult. That is, elderly patients with PD who demonstrate low executive function are expected to have a higher risk of these cognitive dysfunctions. One survey of senior citizens' adoption of home electronic appliances and information devices revealed that more than $50 \%$ owned devices such as personal computers, mobile phones, and DVD players. A national survey in Japan showed that the rate of Internet use among people aged $60-79$ years climbed from $43 \%$ in 2008 to $61 \%$ in 2012 , and the rate is increasing each year [36]. Therefore, elderly people's ability to use information devices and information systems might greatly influence their daily lives. Thus, in order to be able to use information devices and electronics, maintaining cognitive function is necessary and indispensable.

Previous studies showed that participation in intellectual activities and the use of information devices are linked with a lower risk of developing cognitive impairment and dementia [37-39], which suggests a reversal of the assumed direction of influence between cognitive function and higher-level functional capacities. The concept of cognitive reserve has recently been highlighted [40]. Cognitive reserve is characterized by cognitive storage, which appears to help prevent cognitive function decline, and which may be strengthened. Therefore, it is important to increase activities that promote cognitive demands, including intellectual activities and information device usage, to strengthen the cognitive reserve and prevent the decline of cognitive function and the progression of dementia.

With respect to social roles, social participation, and information gathering, there were no significant differences among participants regarding whether executive function was impaired. Overall, patients with PD scored lower than HC on these measures. These findings support previous work indicating that social participation is affected by several factors other than aging-related physical decline, such as socioeconomic status, lifestyle, age, and gender [41], suggesting that cognitive function is not the only cause of lack of social participation.

Despite these findings, both social participation and intellectual activities seem important in preventing dementia [42]. It has been reported that older adults who have infrequent social interaction have an increased risk of developing dementia. The scale of these social networks is an important factor in preventing dementia [43]. That is, it is possible to indirectly activate cognitive function through participation in social networking and interaction with others. One study of patients with PD reported that habitual leisure time activities correlate with cognitive function and emotions [44]. The authors suggest that reducing sedentary lifestyles and promoting habitual leisure time activities (physical and nonphysical leisure activities) might be beneficial in preventing cognitive decline and apathy. The maintenance of an active lifestyle, even in PD patients with motor symptoms, might therefore be beneficial. However, in order to promote social participation, it is necessary to first ascertain the factors that inhibit participation in patients with PD.

The present study is the first to clarify the association between neuropsychological characteristics and higher-level functional capacity in patients with PD. However, some limitations must be noted. First, we were not able to categorize participants by gender and duration of symptoms because the sample size was small. Second, HC were mature participants that lived in our region, who agreed to voluntarily participate after having been publicly recruited. Therefore, there is a possibility that participants' motivation and health awareness were generally high, indicating a potential bias in the sample selection. Third, we used a comprehensive neuropsychological battery to evaluate participants, but this did not include visual 
memory or visual-spatial function examinations. Since these abilities tend to decline with age, they should be assessed in future studies. Fourth, the severity of PD symptoms is an important influence on higher-level functional capacity (in addition to executive function). However, our assessment of symptom severity was based on the HY staging system and did not include the Unified Parkinson's Disease Rating Scale (UPDRS). Compared to the HY staging system, the UPDRS permits a more detailed evaluation of severity level. Examining the relationship between higher-level functional capacity and development of PD symptoms using the UPDRS system is desirable. Furthermore, we examined neuropsychological function and higher-level functional capacity only once in this study. Therefore, we do not know how higher-level functional capacity changes with respect to changes in cognitive function.

In conclusion, our results showed that the higher-level functional capacity of patients with PD declines in comparison to that of $\mathrm{HC}$, and that executive function influences the decline. These findings imply that an increase in educational interventions that promote social and intellectual activities might be effective, and psychological interventions involving cognitive training related to cognitive function might be beneficial for PD patients. Hindle et al. [45] conducted a meta-analysis of studies focusing on the effect of nonpharmacological interventions, such as cognitive training, exercises, physical therapy, and deep brain stimulation, on the cognitive function of PD patients. However, only one study provided a high level of evidence (i.e. using randomized controlled trials and a very low risk of bias). This suggests that research on cognitive training and its influence on cognitive impairment in PD and dementia patients is both quantitatively and qualitatively limited. By way of contrast, there are ample reports of the effectiveness of psychological interventions for patients with psychiatric disorders (e.g. schizophrenia), in which cognitive rehabilitation has been implemented to prevent decline in cognitive function and to improve social function [46]. It may be possible to learn from such positive interventions and apply them to patients with PD to establish a support system that can help maintain and improve cognitive function and higher-level functional capacity in these patients.

\section{Acknowledgement}

We thank the participants and their families. This study was supported by a Grant-in-Aid for JSPS Fellows (242666), a Grant-in-Aid for Scientific Research (B 26285155) and a Grantin-Aid for Scientific Research on Innovative Areas (26118707) from the Japan Society for the Promotion of Science (JSPS).

\section{References}

$>1$ Klepac N, Trkulja V, Relja M, Babić T: Is quality of life in non-demented Parkinson's disease patients related to cognitive performance? A clinic-based cross-sectional study. Eur J Neurol 2008;15:128-133.

-2 Duncan GW, Khoo TK, Yarnall AJ, O’Brien JT, Coleman SY, Brooks DJ, Barker RA, Burn DJ: Health-related quality of life in early Parkinson's disease: the impact of nonmotor symptoms. Mov Disord 2014;29:195-202.

-3 Lawson RA, Yarnall AJ, Duncan GW, Khoo TK, Breen DP, Barker RA, Collerton D, Taylor JP, Burn DJ: Quality of life and mild cognitive impairment in early Parkinson's disease: does subtype matter? J Parkinsons Dis 2014; 4:331-336.

4 Aarsland D, Brønnick K, Williams-Gray C, Weintraub D, Marder K, Kulisevsky J, Burn D, Barone P, Pagonabarraga J, Allcock L, Santangelo G, Foltynie T, Janvin C, Larsen JP, Barker RA, Emre M: Mild cognitive impairment in Parkinson disease: a multicenter pooled analysis. Neurology 2010;75:1062-1069.

5 Aarsland D, Brønnick K, Larsen JP, Tysnes OB, Alves G; Norwegian ParkWest Study Group: Cognitive impairment in incident, untreated Parkinson disease: the Norwegian ParkWest study. Neurology 2009;72:1121-1126. 
Miura et al.: Neuropsychological Characteristics and Their Association with

Higher-Level Functional Capacity in Parkinson's Disease

6 Carlson MC, Fried LP, Xue QL, Bandeen-Roche K, Zeger SL, Brandt J: Association between executive attention and physical functional performance in community-dwelling older women. J Gerontol B Psychol Sci Soc Sci 1999;54:S262-S270.

7 Cahn DA, Sullivan EV, Shear PK, Pfefferbaum A, Heit G, Silverberg G: Differential contributions of cognitive and motor component processes to physical and instrumental activities of daily living in Parkinson's disease. Arch Clin Neuropsychol 1998;13:575-583.

-8 Rosenthal E, Brennan L, Xie S, Hurtig H, Milber J, Weintraub D, Karlawish J, Siderowf A: Association between cognition and function in patients with Parkinson disease with and without dementia. Mov Disord 2010;25: 1170-1176.

-9 Martin RC, Triebel KL, Kennedy RE, Nicholas AP, Watts RL, Stover NP, Brandon M, Marson DC: Impaired financial abilities in Parkinson's disease patients with mild cognitive impairment and dementia. Parkinsonism Relat Disord 2013;19:986-990.

10 Pirogovsky E, Schiehser DM, Obtera KM, Burke MM, Lessig SL, Song DD, Litvan I, Filoteo JV: Instrumental activities of daily living are impaired in Parkinson's disease patients with mild cognitive impairment. Neuropsychology 2014;28:229-237.

11 Lawton MP: Research, planning, and action for the elderly; in Kent D, Kastenbaum R, Sherwood S (eds): Research, Planning, and Action for the Elderly. New York, Behavioral Publications, 1972.

12 Koyano W, Shibata H, Nakazato K, Haga H, Suyama Y: Measurement of competence in the elderly living at home: development of index of competence. Jpn J Public Health 1987;34:109-114.

13 Masui Y, Inagaki H, Yoshida Y, Iwasa H, Yoshida H, Kikuchi K, Yoshida H, Nonaka K, Shimada H, Otuka R, Susuki T: Development of a new 'Index of Competence' reflecting improved health status of the contemporary community-dwelling older adults: reliability and validity of the Japan Science and Technology Agency Index of Competence (JST-IC). Jpn J Gerontol 2014;36:235.

14 Rowe JW, Kahn RL: Human aging: usual and successful. Science 1987;237:143-149.

15 Heaton RK, Chelune GJ, Talley JK, Kay GG, Curtiss G: Wisconsin Card Sorting Test Manual: Revised and Expanded. Odessa, Psychological Assessment Resources, 1993.

16 Reitan RM, Wolfson D: The Halstead-Reitan Neuropsychological Test Battery. Tucson, Neuropsychology Press, 1985.

17 Matsui M, Yuuki H, Kato K, Takeuchi A, Nishiyama S, Bilker WB, Kurachi M: Schizotypal disorder and schizophrenia: a profile analysis of neuropsychological functioning in Japanese patients. J Int Neuropsychol Soc 2007;13:672-682.

18 Wechsler D: Wechsler Adult Intelligence Scale-Third Edition. San Antonio, The Psychological Corporation, 1997.

19 Lezak MD, Howieson DB, Loring DW, Hannay HJ, Fischer JS: Neuropsychological Assessment, ed 4. Oxford, Oxford University Press, 2004.

20 Matsui M, Yuuki H, Kato K, Kurachi M: Impairment of memory organization in patients with schizophrenia or schizotypal disorder. J Int Neuropsychol Soc 2006;12:750-754.

21 Evans AH, Katzenschlager R, Paviour D, O’Sullivan JD, Appel S, Lawrence AD, Lees AJ: Punding in Parkinson's disease: its relation to the dopamine dysregulation syndrome. Mov Disord 2004;19:397-405.

-22 Matsuoka K, Uno M, Kasai K, Koyama K, Kim Y: Estimation of premorbid IQ in individuals with Alzheimer's disease using Japanese ideographic script (Kanji) compound words: Japanese version of National Adult Reading Test. Psychiatry Clin Neurosci 2006;60:332-339.

23 Okada K, Kobayashi S, Aoki K, Suyama N, Yamaguchi S: Assessment of motivational less in poststroke patients using the Japanese version of Starkstein's Apathy Scale (in Japanese). Jpn J Stroke 1998;20:318-323.

24 Uemura A, Oka Y, Tsuboi R, Fujii S, Shimizu Y, Horiba M, et al: Factors affecting early decline of executive function after subthalamic nucleus stimulation in Parkinson's. Adv Parkinson Dis 2013;2:75-80.

-25 Gold JM, Randolph C, Carpenter CJ, Goldberg TE, Weinberger DR: Forms of memory failure in schizophrenia. J Abnorm Psychol 1992;101:487-494.

26 Delis DC, Kramer JH, Kaplan E, Ober BA: California Verbal Learning Test: Adult Version. Manual. San Antonio, The Psychological Corporation, 1987.

27 Koyano W, Shibata H, Nakazato K, Haga H, Suyama Y: Measurement of competence: reliability and validity of the TMIG Index of Competence. Arch Gerontol Geriatr 1991;13:103-116.

28 Kudlicka A, Clare L, Hindle JV: Executive functions in Parkinson's disease: systematic review and metaanalysis. Mov Disord 2011;26:2305-2315.

29 Dirnberger G, Jahanshahi M: Executive dysfunction in Parkinson's disease: a review. J Neuropsychol 2013;7: 193-224.

30 Song SK, Lee JE, Park HJ, Sohn YH, Lee JD, Lee PH: The pattern of cortical atrophy in patients with Parkinson's disease according to cognitive status. Mov Disord 2011;26:289-296.

-31 Gallagher C, Bell B, Bendlin B, Palotti M, Okonkwo O, Sodhi A, Wong R, Buyan-Dent L, Johnson S, Willette A, Harding S, Ninman N, Kastman E, Alexander A: White matter microstructural integrity and executive function in Parkinson's disease. J Int Neuropsychol Soc 2013;19:349-354.

-32 Zheng Z, Shemmassian S, Wijekoon C, Kim W, Bookheimer SY, Pouratian N: DTI correlates of distinct cognitive impairments in Parkinson's disease. Hum Brain Mapp 2014;35:1325-1333. 
-33 Marshall GA, Rentz DM, Frey MT, Locascio JJ, Johnson KA, Sperling RA; Alzheimer's Disease Neuroimaging Initiative: Executive function and instrumental activities of daily living in mild cognitive impairment and Alzheimer's disease. Alzheimers Dement 2011;7:300-308.

34 Iwasa H, Suzuki T, Yoshida H, Kim H, Sinmei M, Yoshida Y, Furuna T, Sugiura M, Nishizawa S, Xiuying H, Shinkai S, Kumagai S, Fujiwara Y, Watanabe S, Yukawa H: Cognitive function as the factor determining higher-level competence in community-dwelling elderly: comprehensive health examination for the community elderly for the prevention of the geriatric syndrome and a bed-ridden state ('otasha-kenshin') (in Japanese). Nihon Koshu Eisei Zasshi 2003;50:950-958.

35 Kumada T, Suto S, Hibi Y: Aging of attention, working memory, and executive function, and cognitive interface design for older adults. Jpn Psychol Rev 2009;52:363-378.

36 Ministry of Internal Affairs and Communications, Japan: White paper 2013: Information and Communications in Japan, 2013.

-37 Verghese J, Lipton RB, Katz MJ, Hall CB, Derby CA, Kuslansky G, Ambrose AF, Sliwinski M, Buschke H: Leisure activities and the risk of dementia in the elderly. N Engl J Med 2003;348:2508-2516.

38 Akbaraly TN, Portet F, Fustinoni S, Dartigues JF, Artero S, Rouaud O, Touchon J, Ritchie K, Berr C: Leisure activities and the risk of dementia in the elderly: results from the Three-City Study. Neurology 2009;73:854861.

-39 Jopp D, Hertzog C: Activities, self-referent memory beliefs, and cognitive performance: evidence for direct and mediated relations. Psychol Aging 2007;22:811-825.

40 Stern Y: What is cognitive reserve? Theory and research application of the reserve concept. J Int Neuropsychol Soc 2002;8:448-460.

41 Ahmad K, Hafeez M: Factors affecting social participation of elderly people: a study in Lahore. J Anim Plant Sci 2011;21:283-289.

-42 Saczynski JS, Pfeifer LA, Masaki K, Korf ESC, Laurin D, White L, Launer LJ: The effect of social engagement on incident dementia: the Honolulu-Asia Aging Study. Am J Epidemiol 2006;163:433-440.

43 Fratiglioni L, Paillard-Borg S, Winblad B: An active and socially integrated lifestyle in late life might protect against dementia. Lancet Neurol 2004;3:343-353.

44 Miura K, Takashima S, Matsui M, Tanaka K: Low frequency of leisure-time activities correlates with cognitive decline and apathy in patients with Parkinson's disease. Adv Park Dis 2014;3:15-21.

45 Hindle JV, Petrelli A, Clare L, Kalbe E: Nonpharmacological enhancement of cognitive function in Parkinson's disease: a systematic review. Mov Disord 2013;28:1034-1049.

46 Wykes T, Reeder C: Cognitive Remediation Therapy for Schizophrenia: Theory and Practice. New York, Taylor \& Francis, 2005. 